\title{
Pure linguistic PROMETHEE I and II methods for heterogeneous MCGDM problems
}

\author{
M. Espinilla ${ }^{1}$, N. Halouani ${ }^{2}$, H. Chabchoub ${ }^{2}$ \\ ${ }^{1}$ University of Jaén \\ Andalucía, Spain \\ E-mail: macarena.espinilla@ujaen.es \\ ${ }^{2}$ University of Economic Sciences and Management \\ Sfax, Tunisia \\ E-mail: halouani.nesrin@gmail.com
}

Received 19 March 2013

Accepted 3 October 2014

\begin{abstract}
The PROMETHEE methods basic principle is focused on a pairwise comparison of alternatives for each criterion, selecting a preference function type that often requires parameters in order to obtain a preference value. When a MCGDM problem is defined in an heterogeneous context, an adequate and common approach is to unify the involved information in linguistic values. However, for each criterion, there is a difficulty to select the specific preference function and define its parameters because they are expressed by crisp values in the unit interval, when the information involved in the problem has been unified into linguistic values. In this paper, a methodology for modeling linguistic preference functions in order to facilitate the selecting of each linguistic preference function type and the definition of its parameters is proposed, providing a more realistic definition of the criteria. Therefore, a generic linguistic preference function is proposed whose inputs and outputs are linguistic values. According to the generic linguistic preference function, six basic preference function types are extended for linguistic values. To do so, a linguistic difference function between linguistic values is defined, being its output, the input of the linguistic preference function. Furthermore, the proposed methodology is integrated in linguistic PROMETHEE I and II for heterogeneous MCGDM problems to obtain partial rankings and a full ranking of alternatives. So, the methodology provides pure linguistic PROMETHEE I and II that offer interpretability and understandability. Finally, the feasibility and applicability of pure linguistic PROMETHEE I and II are illustrated in a case study for the selection of a green supplier.
\end{abstract}

Keywords: PROMETHEE, linguistic preferences, linguistic difference function, linguistic preference functions, heterogeneous information, MCGDM, outranking method.

\section{Introduction}

Multicriteria decision-making $(\mathrm{MCDM})^{9,19,27,34}$ methods establish procedures to select the best alternative to solve a decision problem from a set of feasible alternatives that are characterized by a set of criteria, usually conflicting. The MCDM methods have been widely used as useful tool due to its broad applications in real world problems $4,29,36,41$. When MCDM methods are extended for groups of decision makers, these methods are denominated multicriteria group decision-making methods 


\section{(MCGDM $^{2,5,17,20}$.}

The preference ranking organization method for enrichment evaluations (PROMETHEE) ${ }^{6}$ belongs to the family of outranking methods to solve MCDM problems. Its main advantages are that consists of a quite simple ranking method and follows a transparent computational procedure that is easy to understand by decision makers and stakeholders ${ }^{9,39}$. Due to these advantages, the method has attracted considerable attention in multiple fields such as supplier selection $^{14,38}$, stock trading ${ }^{3}$, resources planing ${ }^{1,13}$ or bankruptcy prediction ${ }^{25}$. A detail review of applications of PROMETHEE methods is shown in Ref. [4].

Among the PROMETHEE family $6,7,8,10$, PROMETHEE I and II methods ${ }^{6}$ are the most well known. The PROMETHEE I offers a partial ordering of the alternatives, while the PROMETHEE II provides the full ranking of the alternatives.

The preference function is the unique feature of the PROMETHEE methods. Each pair of alternatives is compared to compute a preference value by means of a selected preference function type for each criterion. Six basic preference function types have been defined ${ }^{11,12}$, in which at most two parameters have to be defined.

It is an evidence that decision makers encounter difficulty in selecting the specific preference function and its parameters ${ }^{26}$ for each criterion. This problem is even harder when multiple decision makers take part in the problem and they may have different background or degree of knowledge about evaluated criteria, which might have different nature (qualitative and quantitative), or be under qualitative uncertainty non-probabilistic. These situations are common in MCGDM problems in which definition contexts are composed by different expression domains (numerical, interval-valued or linguistic $)^{24,28,33,35}$.

Some linguistic PROMETHEE I and II have been proposed ${ }^{15,22,43}$ to deal with heterogeneous frameworks by means of the fusion approach ${ }^{24}$, which unifies the information in 2-tuple linguistic values ${ }^{23,29}$ because this approach has been proven as fairly suitable to cope with heterogeneous contexts ${ }^{18}$.
However, in such linguistic PROMETHEE I and II, decision makers have serious difficulties to select the preference function type and define its parameters for each criterion ${ }^{26}$ due to the fact that they are expressed by crisp values in the unit interval. Preference functions are generally difficult to understand and hard to define its parameters with precision.

Therefore, crisp values seem that are not always suitable to express the preference function in order to solve MCGDM problems defined in heterogeneous contexts. In this kind of problems, a much more realistic approach would be to use linguistic values instead of crisp values in the preference functions and their parameters, providing linguistic inputs and outputs in order to improve the selection of the preference function type for each criterion, offering better interpretability and understanding.

Bearing the above in mind, this paper proposes a methodology for modeling linguistic preference functions in order to facilitate the selecting of each linguistic preference function type and the definition of its parameters. To do so, a generic linguistic preference function is proposed such that its inputs and outputs are linguistic values. Moreover, six preference function types are extended for linguistic values according to such generic linguistic preference function. For each criterion, the input of the linguistic preference function is the comparison of the assessments of each pair of alternatives, which are unified in 2-tuple linguistic values. Therefore, a linguistic difference function is also proposed in this methodology to compute a linguistic difference value between a pair of 2-tuple linguistic values. The output of the linguistic preference function expresses the preference value of each pair of alternatives with respect to a criterion. So, in order to maintain the interpretability and understandability of the preference functions, the preference value will be also expressed by means of a linguistic value.

Furthermore, this paper proposes the integration of the methodology for modeling linguistic preference functions in linguistic PROMETHEE I and II methods within MCGDM problems defined in heterogeneous contexts. Such integration provides two pure linguistic PROMETHEE I and II methods that offer better interpretability and understandability in 
the involved steps to solve MCGDM problems.

Finally, the feasibility and applicability of the pure linguistic PROMETHEE I and II are examined with a MCGDM problem to select a green supplier by means of a case study.

The rest of this paper is organized as follows. In the following section, some necessary concepts that will be used in our proposal are reviewed. In Section 3, the methodology for modeling linguistic preference functions is proposed. In Section 4, pure linguistic PROMETHEE I and II methods, which integrate the proposed methodology, are presented for addressing heterogeneous MCGDM problems. In Section 5, an illustrative case study to select a green suplir is presented. Finally, in Section 6, conclusions are pointed out.

\section{Preliminaries}

Here, it is reviewed basic concepts about PROMETHEE I and II methods, then, it is reviewed the fusion approach ${ }^{24}$ to deal with heterogeneous information due to the fact that both will be used in our approaches.

\subsection{PROMETHEE-based outranking methods}

The PROMETHEE I and II methods were initially developed by Brans ${ }^{6}$ and extended ${ }^{12}$ later on. In PROMETHEE I and II methods, assessments about a set of alternatives $A=\left\{a_{i}, i=1, \ldots, M\right\}$ are provided with respect to a set of criteria $C=\left\{c_{j}, j=\right.$ $1, \ldots, N\}$.

Each pair of alternatives is compared for each criterion, computing the preference value of the alternative $a_{i}$ over the alternative $a_{m}$. So, the preference value of $a_{i}$ over $a_{m}$ regarding criterion $c_{j}$ is denoted as: $P_{j}\left(d_{j}\left(f_{j}\left(a_{i}\right), f_{j}\left(a_{m}\right)\right)\right)$, in which $d\left(f_{j}\left(a_{i}\right), f_{j}\left(a_{m}\right)\right)$ represents the difference value of the assessment of alternative $f_{j}\left(a_{i}\right)$ with the assessment of the alternative $f_{j}\left(a_{m}\right)$, corresponding to the criterion $c_{j}$. Six different preference function types $P_{j}$, were defined ${ }^{12,21}$ and expressed by crisp values in the unit interval.

The preference value of alternative $a_{i}$ over $a_{m}$, is evaluated for each criterion $c_{j}$, and the preference indexes are computing by using a weight vec- tor $W=\left(w_{1}, \ldots, w_{N}\right)$, in which $w_{j}$, represents the measure for the relative importance of the criterion $c_{j}$. The aggregated preference index of $a_{i}$ over $a_{m}$ is then determined by:

$$
\pi\left(a_{i}, a_{m}\right)=\sum_{j=1}^{N} w_{j} P_{j}\left(d_{j}\left(f_{j}\left(a_{i}\right), f_{j}\left(a_{m}\right)\right)\right)
$$

The leaving flow of each alternative $a_{i}$ represents a measure for the strength of alternatives, i.e, how much $a_{i}$ dominates all the other alternatives. The leaving flow of the alternative $a_{i}$ is given by:

$$
\phi\left(a_{i}\right)^{+}=\frac{1}{M-1} \sum_{m=1, m \neq i}^{M} \pi\left(a_{i}, a_{m}\right)
$$

In a similar way, the entering flow of $a_{i}$ represents a measure for the weakness of the alternatives, i.e., how much $a_{i}$ is dominated by all the other alternatives. The entering flow of the alternative $a_{i}$ is given by:

$$
\phi\left(a_{i}\right)^{-}=\frac{1}{M-1} \sum_{m=1, m \neq i}^{M} \pi\left(a_{m}, a_{i}\right)
$$

PROMETHEE I computes partial ranking for each alternative, assuming that the best alternative should offer the higher leaving flow and the lower entering flow. To do so, PROMETHEE I computes a partial preorder on the set of alternatives, building a preference $P^{I}$, an indifference $I^{I}$ and an incomparability $R^{I}$ relations ${ }^{9}$. In particular:

$$
\begin{gathered}
a_{i} P^{I} a_{m} \Longleftrightarrow\left\{\begin{array}{l}
\phi^{+}\left(a_{i}\right)>\phi^{+}\left(a_{m}\right) \wedge \phi^{-}\left(a_{m}\right)>\phi^{-}\left(a_{i}\right) \vee \\
\phi^{+}\left(a_{i}\right)=\phi^{+}\left(a_{m}\right) \wedge \phi^{-}\left(a_{m}\right)>\phi^{-}\left(a_{i}\right) \vee \\
\phi^{+}\left(a_{i}\right)>\phi^{+}\left(a_{m}\right) \wedge \phi^{-}\left(a_{m}\right)=\phi^{-}\left(a_{i}\right)
\end{array}\right. \\
a_{i} I^{I} a_{m} \Longleftrightarrow \phi^{+}\left(a_{i}\right)=\phi^{+}\left(a_{m}\right) \wedge \phi^{-}\left(a_{i}\right)=\phi^{-}\left(a_{m}\right) \\
a_{i} R^{I} a_{m} \Longleftrightarrow\left\{\begin{array}{l}
\phi^{+}\left(a_{i}\right)>\phi^{+}\left(a_{m}\right) \wedge \phi^{-}\left(a_{i}\right)>\phi^{-}\left(a_{m}\right) \vee \\
\phi^{+}\left(a_{i}\right)<\phi^{+}\left(a_{m}\right) \wedge \phi^{-}\left(a_{i}\right)<\phi^{-}\left(a_{m}\right)
\end{array}\right.
\end{gathered}
$$

In order to compute a complete order, PROMETHEE II computes the net outranking flow as:

$$
\phi\left(a_{i}\right)=\phi\left(a_{i}\right)^{+}-\phi\left(a_{i}\right)^{-}
$$

Therefore, PROMETHEE II computes a complete ranking of the set of alternatives in which the 
best alternative corresponds to the alternative with the highest net flow. So, in a natural way, a preference $P^{I I}$ and an indifference $I^{I I}$ relations are defined as follow:

$$
\begin{aligned}
& a_{i} P^{I I} a_{m} \Longleftrightarrow \phi\left(a_{i}\right)>\phi\left(a_{m}\right) \\
& a_{i} I^{I I} a_{m} \Longleftrightarrow \phi\left(a_{i}\right)=\phi\left(a_{m}\right)
\end{aligned}
$$

It is noteworthy that PROMETHEE I and II for MCGDM problems ${ }^{20}$ provide an extension to the traditional methods in order to take into account a group of decision makers, aggregating individual preference indexes.

\subsection{Fusion approach to deal with heterogeneous context}

In this paper, an heterogeneous framework is considered, in which decision makers can express their assessments by means of different expression domains: numerical domain, interval-valued domain and any linguistic term set. In this section, it is reviewed the fusion approach ${ }^{24}$ based on the 2-tuple linguistic representation model ${ }^{23}$ to deal with heterogeneous information.

The scheme of the fusion approach, which is based on the unification of the heterogeneous information into a linguistic domain, is carried out with the following two steps (see Figure 1) that are reviewed.

1. Transformation of the heterogeneous information into fuzzy sets in a linguistic domain.
The heterogeneous information is unified into a selected linguistic domain called Basic Linguistic Term Set (BLTS) and noted as $S_{B L T S}=$ $\left\{s_{i}, i=0, \ldots, g\right\}$ that is chosen with the aim of keeping as much knowledge as possible ${ }^{24}$. Hence, each assessment is transformed by using an adequate transformation function, according to its expression domain:

(a) Numerical domain. When $v \in[0,1]$, the numerical transformation function

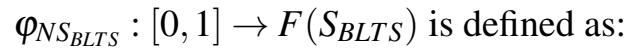

$$
\varphi_{N S_{B L T S}}(v)=\sum_{i=0}^{g}\left(s_{i} / \gamma_{i}\right)
$$

where $\gamma_{i}=\mu_{s_{i}}(v) \in[0,1]$ is the membership degree of $v$ to $s_{i} \in S_{B L T S}$.

(b) Interval domain. When $v \in P([0,1])$, the interval transformation function $\varphi_{I S_{B L T S}}$ : $P([0,1]) \rightarrow F\left(S_{B L T S}\right)$, is defined as:

$$
\varphi_{I S_{B L T S}}(v)=\sum_{i=0}^{g}\left(s_{i} / \gamma_{i}\right)
$$

where $\gamma_{l}^{i}=\max _{y} \min \left\{\mu_{I}(y), \mu_{s_{l}}(y)\right\}$, with $l=\{0, \ldots, g\}$, being $\mu_{I}(\cdot)$ and $\mu_{s_{i}}(\cdot)$ membership functions associated with the interval $I \in P([0,1])$ and the term $s_{l} \in$ $S_{B L T S}$, respectively.

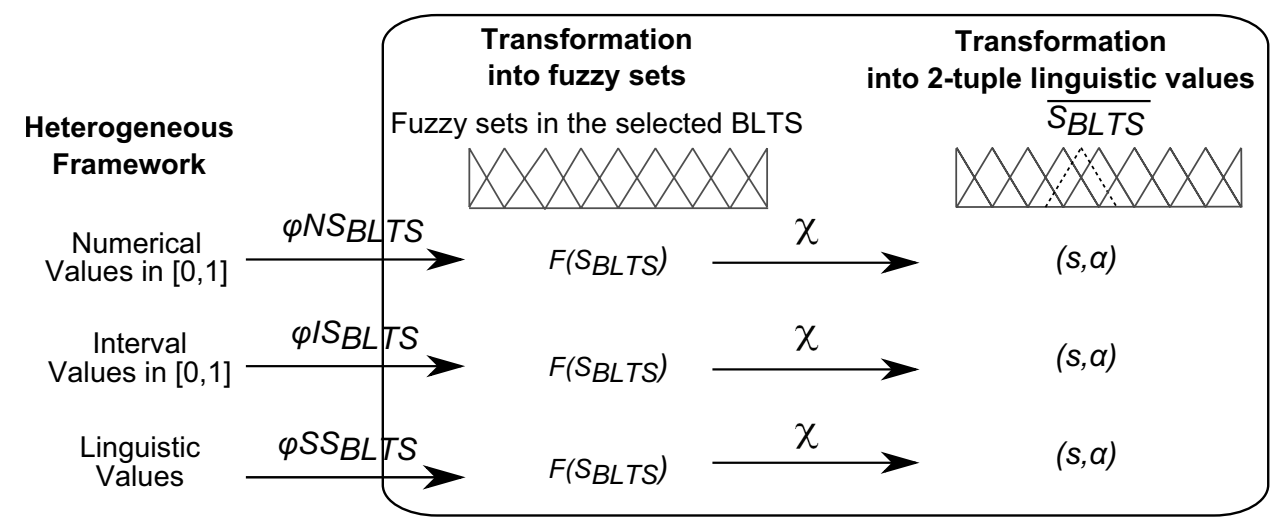

Figure 1: Fusion approach to deal with heterogeneous context. 
(c) Linguistic domain. When $v \in S^{k}$, such that $S^{k}=\left\{s_{0}^{k}, \ldots, s_{g_{k}}^{k}\right\}$ and $g_{k}<g$, the linguistic transformation function $\varphi_{S^{k} S_{B L T S}}$ is defined as:

$$
\varphi_{S^{k} S_{B L T S}}\left(s_{l}^{k}\right)=\sum_{i=0}^{g}\left(s_{i} / \gamma_{i}\right)
$$

where $\gamma_{i}=\max _{y} \min \left\{\mu_{s_{l}}(y), \mu_{s_{i}}(y), \quad i=\right.$ $0, \ldots, g\}$.

2. Transformation of fuzzy sets into 2-tuple linguistic values.

In this process, the previous fuzzy sets are conducted into 2-tuple linguistic values which facilitate the computations and produce interpretable results ${ }^{23,37}$.

The 2-tuple linguistic model represents the information by means of a pair of values $(s, \alpha)$, where $s$ is a linguistic term with syntax and semantics, and $\alpha$ is a numerical value that represents the symbolic translation.

Definition $1{ }^{23}$ Let $S=\left\{s_{0}, \ldots, s_{g}\right\}$ be a set of linguistic terms. The 2-tuple set associated with $S$ is defined as $\bar{S}=S \times[-0.5,0.5)$. The function $\Delta_{S}:[0, g] \longrightarrow \bar{S}$ is defined by:

$$
\Delta_{S}(\beta)=\left(s_{i}, \alpha\right), \text { with }\left\{\begin{array}{l}
i=\operatorname{round}(\beta) \\
\alpha=\beta-i,
\end{array}\right.
$$

where round $(\cdot)$ obtains the integer number $i \in\{0,1, \ldots, g\}$ closest to $\beta$.

Proposition 1 Let $S=\left\{s_{0}, \ldots, s_{g}\right\}$ be a linguistic term set and $\left(s_{i}, \alpha\right)$ be a 2-tuple linguistic value. There is always a function $\Delta_{S}^{-1}$ such that from a 2-tuple linguistic value, it returns its equivalent numerical value $\beta \in[0, g]$ as $\Delta_{S}^{-1}\left(s_{i}, \alpha\right)=i+\alpha$.

The 2-tuple computational model ${ }^{23}$ is based on functions $\Delta_{S}^{-1}$ and $\Delta_{S}$ to operate with 2tuple linguistic values in a precise way. So, the results previously obtained, which are expressed by fuzzy sets $F\left(S_{B L T S}\right)$, are transformed into 2-tuple linguistic values in the BLTS by the function $\chi$ that is defined as:

$$
\begin{gathered}
\chi: F\left(S_{B L T S}\right) \rightarrow \overline{S_{B L T S}} \\
\chi\left(\left\{\left(s_{0}, \gamma_{0}\right),\left(s_{1}, \gamma_{1}\right), \ldots,\left(s_{g}, \gamma_{g}\right)\right\}\right)= \\
\Delta_{S}\left(\frac{\sum_{i=0}^{g} i \gamma_{i}}{\sum_{i=0}^{g} \gamma_{i}}\right)=(s, \alpha)=\bar{s} \in \overline{S_{B L T S}} .
\end{gathered}
$$

Once the heterogeneous information is expressed in 2-tuple linguistic values in the BLTS, the 2-tuple linguistic computation model ${ }^{23}$ can be carried out to compute linguistic results in $\overline{S_{B L T S}}$, using 2-tuple linguistic aggregation operators ${ }^{30,31,40,42}$.

\section{Methodology for modeling linguistic preference functions}

In this section, it is proposed a methodology for modeling linguistic preference functions in order to improve the determination of the preference function type and setting its parameters by means of linguistic values, providing a more realistic definition of criteria to solve MCGDM problems defined in heterogeneous frameworks.

Our methodology proposes to unify the heterogeneous information in 2-tuple linguistic values. Then, by means of a linguistic difference function, a linguistic difference value is computed for each pair of alternatives respect to each criterion. The linguistic outcome with this difference function will be the input of the linguistic preference function for each criterion. A generic linguistic preference function is proposed whose inputs and output are linguistic values. The preference value of each pair of alternatives with respect to each criterion, i.e., the output of the preference function, will be expressed in a linguistic scale to maintain the interpretability. Finally, in order to facilitate the selection of each preference function type and the definition of its parameters, six basic linguistic preference function types are extended for linguistic values according to the generic linguistic preference function. 


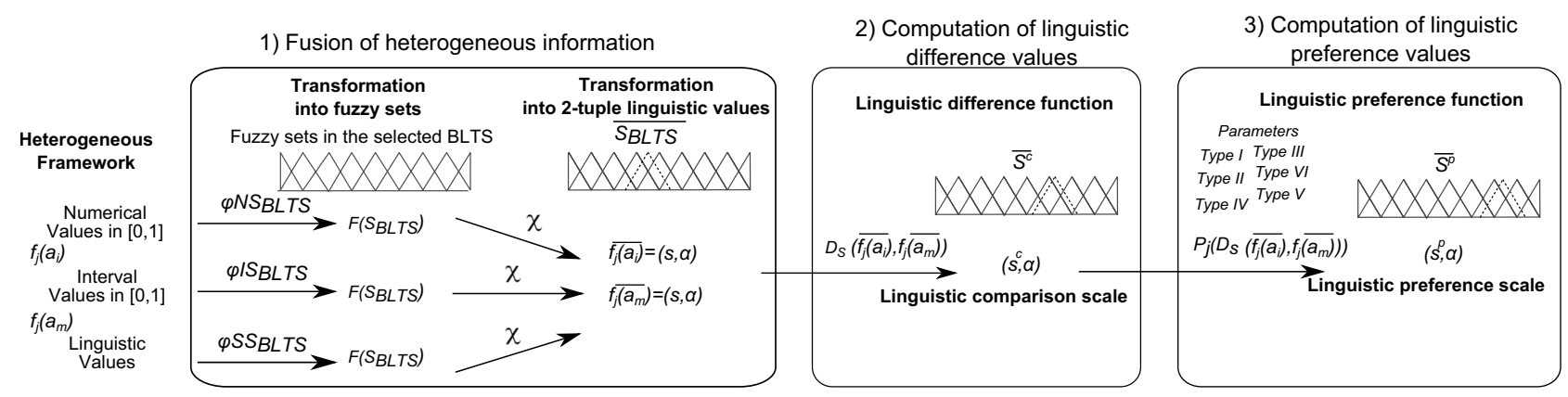

Figure 2: Methodology for modeling linguistic preference function.

The methodology for modeling linguistic preference functions is composed by three phases shown in Figure 2. The following subsections present in further detail each phase.

\subsection{Fusion of heterogeneous information}

In a MCGDM problem defined in an heterogeneous context, assessments of alternatives are expressed in different expression domains (numerical, intervalvalued or linguistic), according to the uncertainty and nature of criteria as well as the background of each decision maker.

In a preference function, each pair of alternatives is compared for each criterion. Therefore, to deal with this framework, heterogeneous information is unified into 2-tuple linguistic values, by using the fusion approach (Section 2.2).

The following subsections present in detail the steps of this phase that were graphically described in Figure 2.

\subsubsection{Transformation into fuzzy sets}

According to the fusion approach, heterogeneous information is conducted into a linguistic domain. To do so, the unification domain $S_{B L T S}$, is chosen ${ }^{24}$ and the heterogeneous information is then conducted by fuzzy sets on $S_{B L T S}$ according to the expression domain, by using the respective transformation functions (see Eqs. (9), (10) and (11)).

\subsubsection{Transformation into 2-tuples linguistic values}

In order to facilitate the understandability of the results, the fuzzy sets are transformed into 2-tuple linguistic values in $S_{B L T S}$ by using the Eq. (13). Therefore, the unified assessment for each criterion $c_{j}$, regarding each alternative $a_{i}$, is expressed in a 2-tuple linguistic value $\overline{f_{j}\left(a_{i}\right)} \in \overline{S_{B L T S}}$.

\subsection{Linguistic difference function between 2-tuple linguistic values}

In order to facilitate the selection of each preference function type and its parameters, we consider that the inputs of the preference function and its parameters must be linguistic values for a better interpretation.

The input of the preference function is the difference value between a pair of unified assessments, which are expressed in 2-tuple linguistic values. Therefore, we propose a linguistic difference function whose linguistic outcome will be the input for the preference function, being the parameters of such function defined in the same linguistic scale in which differences are expressed.

The linguistic difference function $D_{S}$ that computes a linguistic difference value between a pair of 2-tuple linguistic values, is defined as:

Definition 2 Let $\left(s_{i}, \alpha_{i}\right)$ and $\left(s_{m}, \alpha_{m}\right)$ be two 2-tuple linguistic values expressed in $S=\left\{s_{0}, \ldots, s_{g}\right\}$ and, $S^{c}=\left\{s_{0}^{c}, \ldots, s_{g^{c}}^{c}\right\}$ a linguistic comparison scale in which difference values will be expressed. The linguistic difference value between $\left(s_{i}, \alpha_{i}\right)$ and $\left(s_{m}, \alpha_{m}\right)$ 
expressed in $\overline{S^{c}}$ is computed by:

$$
\begin{gathered}
D_{S}: \bar{S} \times \bar{S} \longrightarrow \overline{S^{c}} \\
D_{S}\left(\left(s_{i}, \alpha_{i}\right),\left(s_{m}, \alpha_{m}\right)\right)= \\
=\Delta_{S}\left(\frac{\left(\left(\Delta_{S}^{-1}\left(s_{i}, \alpha_{i}\right)-\Delta_{S}^{-1}\left(s_{m}, \alpha_{m}\right)\right)+g\right)}{2 \cdot g} \cdot g^{c}\right)
\end{gathered}
$$

Therefore, a linguistic difference value between a pair of 2-tuple linguistic values $\left(s_{i}, \alpha_{i}\right)$ and $\left(s_{m}, \alpha_{m}\right)$, is expressed in the linguistic comparison scale $S^{c}$, whose granularity is selected according to the knowledge to interpret the difference between pairs of alternatives by using a bipolar scale ${ }^{16}$, due to the presence of the neutral point, separating positive differences from negatives ones. It is noteworthy that, as pointed out by Miller ${ }^{32}$, most decision makers cannot handle more than 9 linguistic values in their decisions.

Example 1 In order to clarify the proposed linguistic difference function, the linguistic difference value is computed between the 2-tuple linguistic values $\left(s_{4}, 0\right)$ and $\left(s_{6}, 0\right)$, which are expressed in $S=\left\{s_{0}, \ldots, s_{8}\right\}$, establishing the linguistic comparison scale $S^{c}=\left\{s_{0}^{c}, \ldots, s_{8}^{c}\right\}$.

$D_{S}\left(\left(s_{4}, 0\right),\left(s_{6}, 0\right)\right)=\Delta_{S}\left(\frac{(4-6)+8}{2 \cdot 8} \cdot 8\right)=\Delta_{S}(3)=$ $\left(s_{3}^{c}, 0\right) \in \overline{S^{c}}$

\subsection{Linguistic preference functions}

In our methodology, inputs and outputs of the preference functions are 2-tuples linguistic values in order to improve the definition of the preference function and its parameters for each criterion.

To do so, the following subsections present, on the one hand, the generic linguistic preference function whose input and output are linguistic values. On the other hand, six basic linguistic preference function types according to such generic linguistic preference function.

\subsubsection{Generic linguistic preference function}

The linguistic preference value of a pair of alternatives with respecto to a criterion is computed by means of a linguistic preference function, using the proposed linguistic difference function.
A generic linguistic preference function to compute the preference value of each pair of alternatives respect to each criterion is given by Definition 3. The input of the preference function is a linguistic difference value of a pair of alternatives $D_{S}\left(f\left(a_{i}\right), f\left(a_{m}\right)\right) \in \overline{S^{c}}$. The output of the preference function, i.e., the preference value is also represented by a linguistic value in a linguistic preference scale $\overline{S^{p}}$ in order to maintain interpretability and understandability.

Definition 3 The generic linguistic preference function $\overline{P_{j}\left(a_{i}, a_{m}\right)}$, that denotes the linguistic preference value expressed in 2-tuple linguistic values in $S^{p}=\left\{s_{0}^{p}, \ldots, s_{g^{p}}^{p}\right\}$, of the linguistic difference value between the alternative $a_{i}$ over alternative $a_{j}$, regarding criterion $c_{j}, D_{S}\left(a_{i}, a_{m}\right)=$ $D_{S}\left(\left(\overline{f_{j}\left(a_{i}\right)}\right),\left(\overline{f_{j}\left(a_{m}\right)}\right)\right) \in \overline{S^{c}}$, is defined as:

$$
\overline{P_{j}\left(a_{i}, a_{m}\right)} \begin{cases}\bar{P}: A \times A \rightarrow \overline{S^{p}} & \\ \left(s_{0}^{p}, 0\right) & \overline{D_{S}\left(a_{i}, a_{m}\right)_{j}} \leqslant\left(s_{\frac{g^{c}}{2}}^{c}, 0\right) \\ F\left[\overline{D_{S}\left(a_{i}, a_{m}\right)_{j}}\right] & \overline{D_{S}\left(a_{i}, a_{m}\right)_{j}}>\left(s_{\frac{g^{c}}{2}}^{c}, 0\right)\end{cases}
$$

being $F: \overline{S^{c}} \rightarrow \overline{S^{p}}$ a function that translates the linguistic difference value expressed in $\overline{S^{c}}$ between a pair of alternatives $\overline{D_{S}\left(a_{i}, a_{m}\right)}, \in \overline{S^{c}}$, with respect to a criterion $c_{j}$, in a linguistic preference value expressed in $\overline{S^{p}}$.

So, $S^{p}=\left\{s_{0}^{p}, \ldots, s_{g p}^{p}\right\}$ is a linguistic term set whose granularity is selected according to the knowledge to interpret the preference value of a pair of alternatives, representing $\left(s_{0}^{p}, 0\right)$ no preference or indifference, and $\left(s_{g^{p}}^{p}, 0\right)$ strict preference.

\subsubsection{Linguistic preference function types and their parameters}

Once the generic linguistic preference function has been defined, six basic linguistic preference function types are extended for linguistic values according to such generic linguistic preference function in order to facilitate the selection of specific preference function and obtain a more realistic definition for each criterion.

The six basic preference function types and their parameters were initially suggested in classi- 
cal PROMETHEE I and $\mathrm{II}^{6}$ and these preference functions are considered sufficient to treat most of the cases encountered in MCGDM problems. However, other linguistic preference function types could also be considered according to the generic linguistic preference function (see Definition 3).

The parameters of each preference function type are expressed in the same linguistic scale that the difference linguistic values $\overline{S^{c}}$, in order to facilitate the selection of each preference function type and the definition of its parameters. At most two parameters have to be defined in each linguistic preference function type: indifference threshold $\left(s^{c}, \alpha\right)_{q}$, strict preference threshold $\left(s^{c}, \alpha\right)_{p}$ and distance $\left(s^{c}, \alpha\right)_{\sigma}$.

Following, the six basic linguistic preference function types are presented as follow:

Type I: Usual criterion. With this function, there is a strict preference value for the pair of alternatives, if there is a positive difference between such pair of alternatives. It is noteworthy that in this function no parameter is required.

$$
P_{j}\left(a_{i}, a_{m}\right) \begin{cases}\left(s_{0}^{p}, 0\right) & {\overline{D_{S}\left(a_{i}, a_{m}\right)_{j}}}_{j} \leqslant\left(s_{\frac{g^{c}}{2}}^{c}, 0\right) \\ \left(s_{g^{p}}^{p}, 0\right) & {\overline{D_{S}\left(a_{i}, a_{m}\right)_{j}}}_{j}>\left(s_{\frac{g^{c}}{2}}^{c}, 0\right)\end{cases}
$$

Type II: Quasi-criterion. The preference value is indifferent as long as the difference between a pair of alternatives does not exceed the indifference threshold $q,\left(s^{c}, \alpha\right)_{q} \in \overline{S^{c}}$. In the case that the difference exceeds this threshold, the preference value is strict. Therefore, the value of indifference threshold $q$, is fixed in this function.

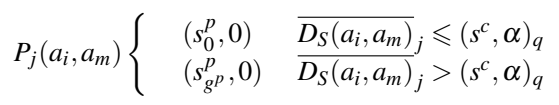

Type III: Criterion with linear preference. This function provides a progressive preference value according to larger differences between a pair of alternatives. The intensity of preference increases linearly until the difference is equal to strict preference threshold $p,\left(s^{c}, \alpha\right)_{p} \in \overline{S^{c}}$. After this threshold, the preference value is strict. Therefore, the value of strict preference threshold $p$, is fixed in this function.

$$
P_{j}\left(a_{i}, a_{m}\right) \begin{cases}\Delta_{S}\left(\frac{\left.\Delta_{S}^{-1}\left(\left(\overline{D_{S}\left(a_{i}, a_{m}\right.}\right) j\right)-\frac{g^{c}}{2}\right)}{\Delta_{S}^{-1}\left(\left(s^{c}, \alpha\right)_{p}-\frac{g^{c}}{2}\right)} \cdot g^{p}\right) & \overline{D_{S}\left(a_{i}, a_{m}\right)_{j}} \leqslant\left(s^{c}, \alpha\right)_{p} \\ \left(s_{g}^{p}, 0\right) & \overline{D_{S}\left(a_{i}, a_{m}\right)_{j}}>\left(s^{c}, \alpha\right)_{p}\end{cases}
$$

Type IV: Level criterion. In this case, the preference value is considered as indifferent when the differences between a pair of alternatives does not exceed the indifference threshold $q,\left(s^{c}, \alpha\right)_{q} \in \overline{S^{c}}$. Between the indifference threshold $q$ and the strict preference threshold $p,\left(s^{c}, \alpha\right)_{p} \in \overline{S^{c}}$, the preference value is medium. After this value, the preference value is strict. Therefore, the value of indifference threshold $q$, and the value of strict preference $p$, are fixed in this function.

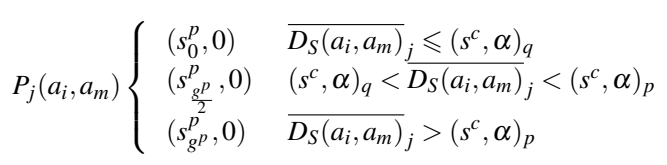

Type V: Criterion with linear preference and indifference area. In this case, the preference value is completely indifferent as long as the difference between a pair of alternatives does not exceed the indifference threshold $q,\left(s^{c}, \alpha\right)_{q} \in \overline{S^{c}}$. Above this value, the preference value grows progressively until this difference is equal to the preference threshold $p,\left(s^{c}, \alpha\right)_{p} \in \overline{S^{c}}$. Therefore, the value of indifference threshold $q$, and the value of strict preference $p$, are fixed in this function.

$$
\begin{aligned}
& P_{j}\left(a_{i}, a_{m}\right)
\end{aligned}
$$

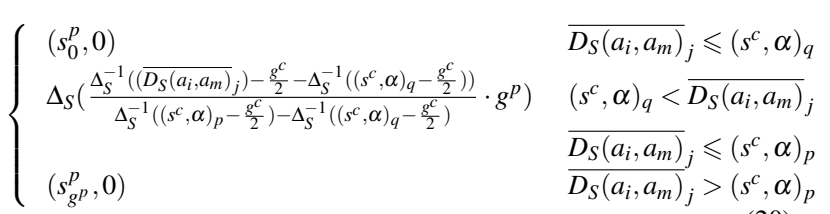

Type VI: Gaussian criterion. In this case, the preference value grows with the difference between a pair of alternatives. The value of $\sigma,\left(s^{c}, \alpha\right)_{\sigma} \in \overline{S^{c}}$ is fixed in this function and it represents the distance between the origin and the point of inflexion of the curve in the normal distribution in statistics.

$$
\begin{aligned}
& P_{j}\left(a_{i}, a_{m}\right) \\
& \left\{\begin{array}{cl}
\left(s_{0}^{p}, 0\right) & \overline{D_{S}\left(a_{i}, a_{m}\right)_{j}} \leqslant\left(s_{\frac{g^{c}}{2}}^{c}, 0\right) \\
\Delta_{S}\left(1-e^{\left.-\frac{\left(\Delta_{S}^{-1}\left(\overline{D_{S}\left(a_{i}, a_{m}\right)}-\frac{g^{c}}{2}\right)^{2}\right.}{2 \times\left(\left(\Delta_{S}^{-1}\left(s^{c}, \alpha\right) \sigma\right)-\frac{g^{c}}{2}\right)^{2}}\right)} \cdot g^{p}\right) & \overline{D_{S}\left(a_{i}, a_{m}\right)_{j}}>\left(s_{\frac{g^{c}}{2}}^{c}, 0\right)
\end{array}\right.
\end{aligned}
$$

Once each preference function type has been selected and its parameters have been defined, a linguistic preference value expressed in $\overline{S^{p}}$ is computed for each $a_{i}$ compared with $a_{m}$, taking into account each criterion $c_{j}$, and its linguistic preference function type $P_{j}$. 
Example 2 An illustrative example to compute a linguistic preference value for a criterion $c_{j}$, by means of the Type III linguistic preference function, is provided in Figure 3. In this example, the linguistic difference value is $\left(s_{6}^{c}, 0\right)$ and the strict preference threshold $p$ is $\left(s_{7}^{c}, 0\right)_{p}$, which are expressed in the linguistic comparative scale $S^{c}=\left\{s_{0}^{c}, \ldots, s_{8}^{c}\right\}$. So, the linguistic preference value is computed by Eq.(18), obtaining $\left(s_{5}^{p}, 0.33\right) \in \overline{S^{p}}$ in the linguistic preference scale $S^{p}=\left\{s_{0}^{p}, \ldots, s_{8}^{p}\right\}$.

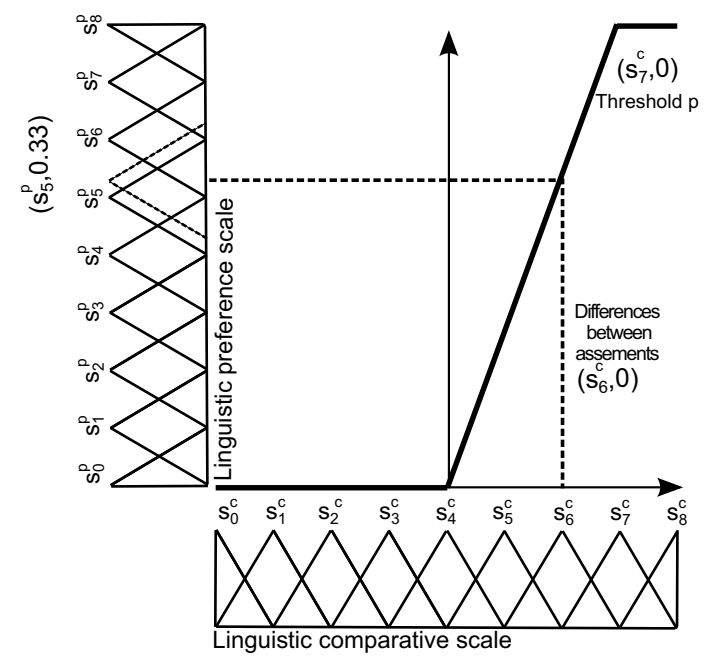

Fig. 3. Linguistic preference value that is computed by Type III linguistic preference function.

\section{Pure linguistic PROMETHEE I and II methods in heterogeneous MCGDM}

In this section, pure linguistic PROMETHEE I and II methods for MCGDM problems defined in heterogeneous contexts are presented, integrating the methodology for modeling linguistic preference function that offers a better interpretability and understandability in the involved steps.

Pure linguistic PROMETHEE I and II methods are summarized in the following 9 steps in which steps 3, 4 and 5 integrate the proposed linguistic methodology.

\section{Step 1. Formulation of the MCGDM problem}

In this step is defined the set of expert $E=\left\{e_{k}, k=\right.$ $1, \ldots, K\}$ and the set of alternatives $A=\left\{a_{i}, i=\right.$
$1, \ldots, M\}$ that are characterized by a set of criteria $C=\left\{c_{j}, j=1, \ldots, N\right\}$.

\section{Step 2. Gathering heterogeneous information}

In this step, each expert $e^{k}$, provides for each alternative $a_{i}$, and for each criterion $c_{j}$, his/her assessment $f_{j}^{k}\left(a_{i}\right)$, in a numerical, interval or linguistic domain.

\section{Step 3. Fusion heterogeneous information}

According to the proposed methodology for modeling linguistic preference functions, the unification domain $S_{B L T S}$, is chosen and the heterogeneous information is unified into 2-tuple linguistic values. First, by using the respective transformation function (see Eqs. (9), (10), (11)) and, second, by using the Eq. (13).

- If $f_{j}\left(a_{i}\right)^{k} \in[0,1]$ then $\chi\left(\varphi_{N S_{B L T S}}\left(f_{j}\left(a_{i}\right)\right)\right)$ is applied, obtaining the unified assessment $\overline{f_{j}\left(a_{i}\right)^{k}} \in$ $\overline{S_{B L T S}}$.

- If $f_{j}\left(a_{i}\right)^{k} \in P([0,1])$ then $\chi\left(\varphi_{I S_{B L T S}} f_{j}\left(a_{i}\right)\right)$ is applied, obtaining the unified assessment $\overline{f_{j}\left(a_{i}\right)^{k}} \in$ $\overline{S_{B L T S}}$.

- If $f_{j}\left(a_{i}\right)^{k} \in S^{k}$ then $\chi\left(\varphi_{S^{k} S_{B L T S}} f_{j}\left(a_{i}\right)\right)$ is applied, obtaining the unified assessment $\overline{f_{j}\left(a_{i}\right)^{k}} \in \overline{S_{B L T S}}$.

\section{Step 4. Computing difference values between unified assessments}

According to the methodology, the computation of the linguistic difference values between unified assessments is carried out. First, a linguistic comparison scale is chosen $S^{c}$, and then the difference value between unified assessments are obtained in $S^{c}$ by Eq. (14): $D_{S}\left(\overline{f_{j}\left(a_{i}\right)^{k}}, \overline{f_{j}\left(a_{m}\right)^{k}}\right) \in \overline{S^{c}}$.

\section{Step 5. Computing individual linguistic preference values}

Computations to obtain individual linguistic preference values are performed. First, the linguistic preference scale is chosen $S^{p}$, and then for each criterion $c_{j}$, its linguistic preference function type $P_{j}$ is selected (Eqs. (16)-(21)) and its parameters are defined in 2-tuple linguistic values in $\overline{S^{c}}$. 
Each linguistic preference value for each expert $e^{k}$, and each alternative $a_{i}$, with regards to alternative $a_{m}$, over criterion $c_{j}$, is computed by means of its linguistic preference function type $P_{j}: \overline{P_{j}\left(a_{i}, a_{m}\right)^{k}} \in$ $\overline{S^{c}}$.

\section{Step 6. Computing aggregated linguistic preference indexes for each decision maker}

A weight vector $W=\left(w_{1}, \ldots, w_{k}\right)$ in which $w_{j}$ represents the measure for the relative importance of the criterion $c_{j}$ is used to compute the individual linguistic preference indexes that are determined by:

$$
\begin{gathered}
\bar{\pi}^{k}: A \times A \rightarrow \overline{S^{p}} \\
\overline{\pi\left(a_{i}, a_{m}\right)^{k}}=\Delta_{S}\left(\sum_{j=1}^{N} w_{j}\left(\Delta_{S}^{-1}\left(\overline{P_{j}\left(a_{i}, a_{m}\right)^{k}}\right)\right)\right)
\end{gathered}
$$

\section{Step 7. Computing aggregated collective linguistic preference indexes}

Individual linguistic preference indexes are aggregated to compute an aggregated collective linguistic preference index for each alternative $a_{i}$, that integrates the opinion of each decision maker $e^{k}$. So, the aggregated collective linguistic preference indexes are determined by:

$$
\begin{gathered}
\bar{\pi}: A \times A \rightarrow \overline{S^{p}} \\
\overline{\pi\left(a_{i}, a_{m}\right)}=\Delta_{S}\left(\frac{\left(\sum_{k=1}^{K} \Delta_{S}^{-1}\left(\overline{\pi\left(a_{i}, a_{m}\right)^{k}}\right)\right)}{K}\right)
\end{gathered}
$$

\section{Step 8. Computing leaving flows and entering flows. Partial rankings}

The leaving flow in the pure linguistic PROMETHEE I method is given by:

$$
\begin{gathered}
\overline{\phi^{+}}: A \rightarrow \overline{S^{p}} \\
\overline{\phi\left(a_{i}\right)^{+}}=\Delta_{S}\left(\frac{\sum_{m=1, m \neq i}^{M} \Delta_{S}^{-1}\left(\overline{\pi\left(a_{i}, a_{m}\right)}\right)}{M-1}\right)
\end{gathered}
$$

The entering flow in the pure linguistic PROMETHEE I method is given by:

$$
\overline{\phi^{-}}: A \rightarrow \overline{S^{p}}
$$

$$
\overline{\phi\left(a_{i}\right)^{-}}=\Delta_{S}\left(\frac{\sum_{m=1, m \neq i}^{M} \Delta_{S}^{-1}\left(\overline{\pi\left(a_{m}, a_{i}\right)}\right)}{M-1}\right)
$$

According to the leaving flows and entering flows of alternatives, partial rankings are computed in the pure linguistic PROMETHEE I method.

\section{Step 9. Computing net flows. Full ranking}

The net flow in the pure linguistic PROMETHEE II method is given by:

$$
\begin{gathered}
\bar{\phi}: A \rightarrow\left[-g^{p}, g^{p}\right] \\
\overline{\phi\left(a_{i}\right)}=\Delta_{S}^{-1}\left(\phi\left(a_{i}\right)^{+}\right)-\Delta_{S}^{-1}\left(\phi\left(a_{i}\right)^{-}\right)
\end{gathered}
$$

According to the net flows of alternatives, a full ranking is computed in the pure linguistic PROMETHEE II method.

\section{Illustrative case study}

In this section, it is presented a case study for the selection of a green supplier, applying pure linguistic PROMETHEE I and II that integrate the methodology for modeling linguistic preference functions in order to obtain partial rankings and a full ranking of feasible green suppliers.

Each step of the pure linguistic PROMETHEE I and II methods is described in further detail below.

\section{Step 1. Formulation of the MCGDM problem}

This case study has been conducted in a company in which three decision makers $E=\left\{e_{1}, e_{2}, e_{3}\right\}$, from different areas with different knowledge background, evaluate a set of suppliers $X=\left\{x_{1}, x_{2}, x_{3}\right\}$, by using different expression domains: Numerical $(\mathrm{N})$, Interval-valued(I) or Linguistic (L). The set of suppliers are characterized by a set of seven criteria $C=\left\{c_{1}, \ldots, c_{7}\right\}$, which are shown in Table 1. 
Table 1. Criteria set description.

\begin{tabular}{|c|l|}
\hline$c_{j}$ & Criterion \\
\hline$c_{1}(\mathrm{~L})$ & $\begin{array}{l}\text { Green capability: The ability to prepare, } \\
\text { produce and deliver green products based on } \\
\text { environmental standards }\end{array}$ \\
\hline$c_{2}(\mathrm{~L})$ & $\begin{array}{l}\text { Quality. The ability to meet quality } \\
\text { specification consistently }\end{array}$ \\
\hline$c_{3}(\mathrm{~L})$ & $\begin{array}{l}\text { Green design. A systematic method to } \\
\text { reduce the environmental impact of products } \\
\text { and processes }\end{array}$ \\
\hline$c_{4}(\mathrm{~L})$ & $\begin{array}{l}\text { Green material. Degree of green and } \\
\text { environmental friendly material in } \\
\text { production process }\end{array}$ \\
\hline$c_{5}(\mathrm{I})$ & $\begin{array}{l}\text { Price: The total cost of products offered as } \\
\text { the price }\end{array}$ \\
\hline$c_{6}(\mathrm{~N})$ & $\begin{array}{l}\text { Re-use rate. The rate of collecting used } \\
\text { products from the field, and distributing or } \\
\text { selling them }\end{array}$ \\
\hline$c_{7}(\mathrm{~N})$ & $\begin{array}{l}\text { Re-cycle rate. The rate of collecting used } \\
\text { products, disassembling and separating to } \\
\text { reprocess }\end{array}$ \\
\hline
\end{tabular}

Specifically, in this case study, each decision maker expresses his/her linguistic assessments in three linguistic domains with different number of linguistic terms. Decision makers $e_{1}, e_{2}$ and $e_{3}$ use the linguistic term sets $S^{5}, S^{7}$ and $S^{9}$, respectively. Each linguistic term set is symmetrically and uniformly distributed and its syntax is as follows:

$S^{5}=\{\operatorname{Null}(\mathrm{N})$, Low $(\mathrm{L}), \operatorname{Medium}(\mathrm{M}), \operatorname{High}(\mathrm{H})$, Perfect $(\mathrm{P})\}$

$S^{7}=\{$ Null (N), VeryLow (VL), Low (L), Medium (M), High (H),

VeryHigh $(\mathrm{VH})$, Perfect $(\mathrm{P})\}$

$S^{9}=\{$ Null (N), AlmostNull (AN), VeryLow (VL), Low (L), Medium (M), High (H),SlightlyHigh (SH), VeryHigh (VH), Perfect (P)\}

\section{Step 2. Gathering heterogeneous information}

The information gathered by the set of decision makers is shown in Tables 2-4.

Table 2. Information provided by $e_{1}$ expressed in $S^{5}$.

\begin{tabular}{|lccccccc|}
\hline$e^{1}$ & $c_{1}$ & $c_{2}$ & $c_{3}$ & $c_{4}$ & $c_{5}$ & $c_{6}$ & $c_{7}$ \\
\hline$a_{1}$ & $\mathrm{M}$ & $\mathrm{L}$ & $\mathrm{M}$ & $\mathrm{M}$ & $59-69$ & 0.61 & 0.77 \\
\hline$a_{2}$ & $\mathrm{H}$ & $\mathrm{H}$ & $\mathrm{M}$ & $\mathrm{H}$ & $66-83$ & 0.79 & 0.88 \\
\hline$a_{3}$ & $\mathrm{P}$ & $\mathrm{H}$ & $\mathrm{H}$ & $\mathrm{P}$ & $80-91$ & 0.87 & 0.97 \\
\hline
\end{tabular}

Table 3. Information provided by $e_{2}$ expressed in $S^{7}$.

\begin{tabular}{|cccccccc|}
\hline$e^{2}$ & $c_{1}$ & $c_{2}$ & $c_{3}$ & $c_{4}$ & $c_{5}$ & $c_{6}$ & $c_{7}$ \\
\hline$a_{1}$ & $\mathrm{H}$ & $\mathrm{L}$ & $\mathrm{H}$ & $\mathrm{H}$ & $63-72$ & 0.63 & 0.75 \\
\hline$a_{2}$ & $\mathrm{VH}$ & $\mathrm{VH}$ & $\mathrm{VH}$ & $\mathrm{VH}$ & $68-81$ & 0.78 & 0.86 \\
\hline$a_{3}$ & $\mathrm{P}$ & $\mathrm{VH}$ & $\mathrm{VH}$ & $\mathrm{P}$ & $80-90$ & 0.88 & 0.92 \\
\hline
\end{tabular}

Table 4. Information provided by $e_{3}$ expressed in $S^{9}$.

\begin{tabular}{|lccccccc|}
\hline$e^{3}$ & $c_{1}$ & $c_{2}$ & $c_{3}$ & $c_{4}$ & $c_{5}$ & $c_{6}$ & $c_{7}$ \\
\hline$a_{1}$ & $\mathrm{M}$ & $\mathrm{L}$ & $\mathrm{M}$ & $\mathrm{M}$ & $60-70$ & 0.65 & 0.75 \\
\hline$a_{2}$ & $\mathrm{SH}$ & $\mathrm{SH}$ & $\mathrm{M}$ & $\mathrm{SH}$ & $70-80$ & 0.76 & 0.84 \\
\hline$a_{3}$ & $\mathrm{VH}$ & $\mathrm{SH}$ & $\mathrm{SH}$ & $\mathrm{VH}$ & $75-90$ & 0.82 & 0.95 \\
\hline
\end{tabular}

\section{Step 3. Fusion heterogeneous information}

In this case study, the selected linguistic domain to unify the information is $\overline{S^{9}}$. The unified information provided by the set of decision makers is shown in Tables 5-7.

Table 5. Unified information provided by $e_{1}$.

\begin{tabular}{|cccccccc|}
\hline$e^{1}$ & $c_{1}$ & $c_{2}$ & $c_{3}$ & $c_{4}$ & $c_{5}$ & $c_{6}$ & $c_{7}$ \\
\hline$a_{1}$ & $(M, 0)$ & $(V L, 0)$ & $(M, 0)$ & $(M, 0)$ & $(H, .13)$ & $(H,-.12)$ & $(S H, .16)$ \\
\hline$a_{2}(S H, 0)$ & $(S H, 0)$ & $(M, 0)$ & $(S H, 0)$ & $(S H,-.03)$ & $(S H, .32)$ & $(V H, .04)$ \\
\hline$a_{3}(V H, 0)$ & $(S H, 0)$ & $(S H, 0)$ & $(V H, 0)$ & $(V H,-.17)$ & $(V H,-.04)$ & $(P,-.24)$ \\
\hline
\end{tabular}

Table 6. Unified information provided by $e_{2}$.

\begin{tabular}{|cccccccc|}
\hline$e^{2}$ & $c_{1}$ & $c_{2}$ & $c_{3}$ & $c_{4}$ & $c_{5}$ & $c_{6}$ & $c_{7}$ \\
\hline$a_{1}(H, 37)$ & $(V L,-.37)$ & $(H, .37)$ & $(H, .37)$ & $(H, .44)$ & $(H, .04)$ & $(S H, 0)$ \\
\hline$a_{2}(V H,-.37)(V H,-.37)$ & $(V H,-.37)(V H,-.37)(S H,-.04)(S H, .24)(V H,-.12)$ \\
\hline$a_{3}(V H, .49)$ & $(V H,-.37)(V H,-.37)(V H, .49)(V H,-.22)(V H, .04)(V H, .36)$ \\
\hline
\end{tabular}

Table 7. Unified information provided by $e_{3}$.

\begin{tabular}{|lccccccc|}
\hline$e^{3}$ & $c_{1}$ & $c_{2}$ & $c_{3}$ & $c_{4}$ & $c_{5}$ & $c_{6}$ & $c_{7}$ \\
\hline$a_{1}(M, 0)$ & $(L, 0)$ & $(M, 0)$ & $(M, 0)$ & $(H, .22)$ & $(H, .2)$ & $(S H, 0)$ \\
\hline$a_{2}(S H, 0)$ & $(S H, 0)$ & $(V H, 0)$ & $(S H, 0)$ & $(S H, 0)$ & $(S H, .08)$ & $(V H,-.28)$ \\
\hline$a_{3}(V H, 0)$ & $(S H, 0)$ & $(S H, 0)$ & $(V H, 0)$ & $(V H,-.36)$ & $(V H,-.44)$ & $(P,-.4)$ \\
\hline
\end{tabular}

\section{Step 4. Computing difference values between unified assessments}

The difference values between unified assessments are expressed in the linguistic comparison scale $S^{c}$ that is shown in Figure 4.

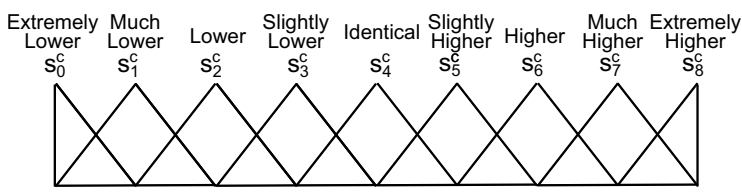

Fig. 4. Linguistic comparison scale

Linguistic difference values are computed by Eq. (14).

\section{Step 5. Computing individual linguistic preference values}

The computation of each individual linguistic preference value for each criterion is expressed in a lin- 
guistic preference scale $\overline{S^{p}}$ with 9 linguistic terms by Eq. (22).

For each criterion $c_{j}$, its linguistic preference function type $P_{j}$, and its parameters are shown in Table 8 , which are expressed in $\overline{S^{c}}$.

Table 8. Linguistic preference functions and its parameters

\begin{tabular}{|c|c|c|}
\hline$c_{j}$ & Type & Parameters \\
\hline$c_{1}$ & Type V - Eq.(20) & $\left(s_{5}^{c}, 0\right)_{q}-\left(s_{6}^{c}, 0\right)_{p}$ \\
\hline$c_{2}$ & Type III - Eq.(18) & $\left(s_{5}^{c}, 0\right)_{p}$ \\
\hline$c_{3}$ & Type III - Eq.(18) & $\left(s_{6}^{c}, 0\right)_{p}$ \\
\hline$c_{4}$ & Type V - Eq.(20) & $\left(s_{5}^{c}, 0\right)_{q}-\left(s_{6}^{c}, 0\right)_{p}$ \\
\hline$c_{5}$ & Type III - Eq.(18) & $\left(s_{5}^{c}, 0\right)_{p}$ \\
\hline$c_{5}$ & Type V - Eq.(20) & $\left(s_{5}^{c}, 0\right)_{q}-\left(s_{6}^{c}, 0\right)_{p}$ \\
\hline$c_{7}$ & Type III - Eq.(18) & $\left(s_{6}^{c}, 0\right)_{p}$ \\
\hline
\end{tabular}

\section{Step 6. Computing aggregated linguistic preference indexes for each decision maker}

Individual linguistic preference indexes are computed by using the following weight vector $W=$ $(.1, .2, .1, .2, .15, .1, .15)$ for the set of criteria. According to selected linguistic preference functions and their parameters (see Table 8), the aggregated linguistic preference indexes for each decision maker $e^{k}$, are computed by Eq. (22), which are shown in Tables 9-11.

Table 9. Aggregated linguistic preference indexes for $e_{1}$.

\begin{tabular}{|cccc|}
\hline$e^{1}$ & $a_{1}$ & $a_{2}$ & $a_{3}$ \\
\hline$a_{1}$ & - & $\left(s_{1}^{p}, .36\right)$ & $\left(s_{1}^{p}, .44\right)$ \\
\hline$a_{2}$ & $\left(s_{1}^{p}, .13\right)$ & - & $\left(s_{1}^{p}, .33\right)$ \\
\hline$a_{3}$ & $\left(s_{1}^{p}, .5\right)$ & $\left(s_{1}^{p}, .17\right)$ & - \\
\hline
\end{tabular}

Table 10. Aggregated linguistic preference indexes for $e_{2}$.

\begin{tabular}{|cccc|}
\hline$e^{2}$ & $a_{1}$ & $a_{2}$ & $a_{3}$ \\
\hline$a_{1}$ & - & $\left(s_{1}^{p}, .37\right)$ & $\left(s_{1}^{p}, .41\right)$ \\
\hline$a_{2}$ & $\left(s_{1}^{p}, .13\right)$ & - & $\left(s_{1}^{p}, .29\right)$ \\
\hline$a_{3}$ & $\left(s_{1}^{p}, .09\right)$ & $\left(s_{1}^{p}, .21\right)$ & - \\
\hline
\end{tabular}

Table 11. Aggregated linguistic preference indexes for $e_{3}$.

\begin{tabular}{|cccc|}
\hline$e^{3}$ & $a_{1}$ & $a_{2}$ & $a_{3}$ \\
\hline$a_{1}$ & - & $\left(s_{1}^{p}, .38\right)$ & $\left(s_{1}^{p}, .42\right)$ \\
\hline$a_{2}$ & $\left(s_{1}^{p}, .11\right)$ & - & $\left(s_{1}^{p}, .28\right)$ \\
\hline$a_{3}$ & $\left(s_{1}^{p}, .08\right)$ & $\left(s_{1}^{p}, .21\right)$ & - \\
\hline
\end{tabular}

\section{Step 7. Computing aggregated collective linguistic preference indexes}

The aggregated collective linguistic preference indexes are computed by the Eq. (23) that are shown in Table 12.

Table 12. Aggregated collective linguistic preference indexes in $S^{p}$.

\begin{tabular}{|cccc|}
\hline$A$ & $a_{1}$ & $a_{2}$ & $a_{3}$ \\
\hline$a_{1}$ & - & $\left(s_{1}^{p}, .37\right)$ & $\left(s_{1}^{p}, .42\right)$ \\
\hline$a_{2}$ & $\left(s_{1}^{p}, .12\right)$ & - & $\left(s_{1}^{p}, .30\right)$ \\
\hline$a_{3}$ & $\left(s_{1}^{p}, .07\right)$ & $\left(s_{1}^{p}, .20\right)$ & - \\
\hline
\end{tabular}

\section{Step 8. Computing leaving flows and entering flows. Partial rankings}

The leaving flows are computed by the Eq. (24) and the entering flows are computed by the Eq. (25) that are shown in Table 13.

Table 13. Computed leaving flows, entering flows and net flows

\begin{tabular}{|cccc|}
\hline$A$ & $\overline{\phi^{+}}$ & $\overline{\phi^{-}}$ & $\phi$ \\
\hline$a_{1}$ & $\left(s_{1}^{p}, .40\right)$ & $\left(s_{1}^{p}, .10\right)$ & 0.30 \\
\hline$a_{2}$ & $\left(s_{1}^{p}, .21\right)$ & $\left(s_{1}^{p}, .28\right)$ & -0.07 \\
\hline$a_{3}$ & $\left(s_{1}^{p}, .13\right)$ & $\left(s_{1}^{p}, .36\right)$ & -0.23 \\
\hline
\end{tabular}

According to the leaving flows and entering flows, the partial rankings are: $a_{1} P^{I} a_{2}, a_{1} P^{I} a_{3}$, $a_{2} P^{I} a_{3}$.

\section{Step 9. Computing net flows. Full ranking}

The net flows are computed by the Eq. (26) and are shown in the fourth column in Table 13.

In this illustrative case study, the value 0.30 is the highest net flow and it corresponds to the supplier $x_{1}$. Therefore, $x_{1}$ is the best supplier for this green selection, being the full ranking: $a_{1} P^{I I} a_{2} P^{I I} a_{3}$.

\section{Conclusions}

Linguistic PROMETHEE I and II methods have been proposed in the literature to solve MCGDM problems defined in heterogeneous contexts, which unify the heterogeneous information into 2-tuple linguistic values. In these methods, for each criterion, a preference function type is selected and its parameters are defined by using crisp values expressed 
in the unit interval to compute a preference value. However, due to the imprecision and uncertainty in some MCGDM problems, decision makers present serious problems to select the preference function type for each criterion and define its parameters.

In this paper, a realistic methodology has been proposed for modeling linguistic preference functions in order to facilitate the selecting of each linguistic preference function type and the definition of its parameters. To do so, a generic linguistic preference function has been proposed in which its input and output are linguistic values, offering a better interpretability and understandability. The six basic linguistic preference function types have been extended for linguistic values according to such generic linguistic preference function. A linguistic difference function has been defined to compute a linguistic difference value between a pair of 2-tuple linguistic values, which is the input of the linguistic preference function. This paper has also presented pure linguistic PROMETHEE I and II methods to solve for heterogeneous MCGDM problems that integrate the proposed methodology, offering a better interpretability and understandability in the involved steps. Finally, the feasibility and applicability of the pure linguistic PROMETHEE I and II methods have been examined in an illustrative case study to select a green supplier.

\section{Acknowledgments}

This paper has been partially supported by the Research Projects TIN2012-31263 and CEATIC-2013001 .

\section{References}

1. M.F. Abu-Taleb and B. Mareschal. Water resources planning in the middle east: Application of the PROMETHEE v multicriteria method. European Journal of Operational Research, 81(3):500 $511,1995$.

2. N. Agell, M. Sanchez, F. Prats, and L. Rosello. Ranking multi-attribute alternatives on the basis of linguistic labels in group decisions. Information Sciences, 209:49-60, 2012.

3. A. Albadvi, S.K. Chaharsooghi, and A. Esfahanipour. Decision making in stock trading: An application of
PROMETHEE. European Journal of Operational Research, 177(2):673-683, 2006.

4. M. Behzadian, R.B. Kazemzadeh, A. Albadvi, and M. Aghdasi. PROMETHEE: A comprehensive literature review on methodologies and applications. European Journal of Operational Research, 200(1):198215, 2010.

5. D. Ben-Arieh and Z. Chen. Linguistic-labels aggregation and consensus measure for autocratic decision making using group recommendations. IEEE Transactions on Systems, Man, and Cybernetics Part A:Systems and Humans, 36(3):558-568, 2006.

6. J.P. Brans. L'ingénièrie de la décision; Elaboration d'instruments d'aide à la décision. La méthode PROMETHEE. In R. Nadeau and M. Landry, editors, L'aide à la décision: Nature, Instruments et Perspectives d'Avenir, pages 183-213, Québec, Canada, 1982. Presses de l'Université Laval.

7. J.P. Brans and B. Mareschal. The PROMETHEEGAIA decision support system for multicriteria investigations. Investigation Operativa, 4(2):107-117, 1994.

8. J.P. Brans and B. Mareschal. The PROMETHEE VI procedure. How to differentiate hard from soft multicriteria problems. Journal of Decision Systems, 4:213-223, 1995.

9. J.P. Brans and B. Mareschal. PROMETHEE methods in Multiple Criteria Decision Analysis: State of the Art Surveys. Springer, New York, 2005.

10. J.P Brans, B. Mareschal, and $\mathrm{Ph}$. Vincke. PROMETHEE: a new family of outranking methods in multicriteria analysis. In J.P Brans, editor, Operational Research, IFORS 84, pages 477-490. North Holland, Amsterdam, 1984.

11. J.P Brans and Ph. Vincke. A preference ranking organization method. Management Science, 31(6):647656, 1985

12. J.P. Brans, Ph. Vincke, and B. Mareschal. How to select and how to rank projects: The PROMETHEE method. European Journal of Operational Research, 24(2):228-238, 1986.

13. Th. Briggs, P.L. Kunsch, and B. Mareschal. Nuclear waste management: An application of the multicriteria PROMETHEE methods. European Journal of Operational Research, 44(1):1-10, 1990.

14. C.-T. Chen, P.-F. Pai, and W.-Z. Hung. An integrated methodology using linguistic PROMETHEE and maximum deviation method for third-party logistics supplier selection. International Journal of Computational Intelligence Systems, 3(4):438-451, 2010.

15. D. Dhouib and S. Elloumi. A new multi-criteria approach dealing with dependent and heterogeneous criteria for end-of-life product strategy. Applied Mathematics and Computation, 218(5):1668-1681, 2011.

16. D. Dubois and H. Prade. An introduction to bipo- 
lar representations of information and preference. International Journal of Intelligent Systems, 23(8):866877, 2008.

17. M. Espinilla, J. Liu, and L. Martínez. An extended hierarchical linguistic model for decision-making problems. Computational Intelligence, 27(3):489-512, 2011.

18. M. Espinilla, I. Palomares, L. Martínez, and D. Ruan. A comparative study of heterogeneous decision analysis approaches applied to sustainable energy evaluation. International Journal on Uncertainty, Fuzziness and Knowledge-based Systems, 20(supp01):159-174, 2012.

19. F.J. Estrella, M. Espinilla, F. Herrera, and L. Martínez. Flintstones: A fuzzy linguistic decision tools enhancement suite based on the 2-tuple linguistic model and extensions. Information Sciences, 280:152-170, 2014.

20. J. Figueira, S. Greco, and M. Ehrgott. Multiple criteria decision analysis: state of the art surveys, volume 78. Springer Verlag, 2005.

21. J.A Geldermann, T.B Spengler, and O.A Rentz. Fuzzy outranking for environmental assessment. case study: Iron and steel making industry. Fuzzy Sets and Systems, 115(1):45-65, 2000.

22. N. Halouani, H. Chabchoub, and J.-M. Martel. PROMETHEE-md-2t method for project selection. European Journal of Operational Research, 195(3):841-849, 2009.

23. F. Herrera and L. Martínez. A 2-tuple fuzzy linguistic representation model for computing with words. IEEE Transactions on Fuzzy Systems, 8(6):746-752, 2000.

24. F. Herrera, L. Martínez, and P.J. Sánchez. Managing non-homogeneous information in group decision making. European Journal of Operational Research, 166(1):115-132, 2005.

25. Y.-C. Hu and C.-J. Chen. A PROMETHEE-based classification method using concordance and discordance relations and its application to bankruptcy prediction. Information Sciences, 181(22):4959-4968, 2011.

26. K. Hyde, H.R. Maier, and C. Colby. Incorporating uncertainty in the PROMETHEE MCDA method. Journal of Multi-Criteria Decision Analysis, 12(4-5):245259, 2003.

27. A. Ishizaka and P. Nemery. Multi-criteria Decision Analysis: Methods and Software. Wiley, 2013.

28. D. F. Li, Z. G. Huang, and G. H. Chen. A systematic approach to heterogeneous multiattribute group decision making. Computers \& Industrial Engineering, 59(4):561 - 572, 2010.

29. L. Martínez and F. Herrera. An overview on the 2tuple linguistic model for computing with words in decision making: Extensions, applications and challenges. Information Sciences, 207(1):1-18, 2012.
30. J.M. Merigó, M. Casanovas, and L. Martínez. Linguistic aggregation operators for linguistic decision making based on the dempster-shafer theory of evidence. International Journal of Uncertainty, Fuzziness and Knowledge-Based Systems, 18(3):287-304, 2010.

31. J.M. Merigó and A.M. Gil-Lafuente. Induced 2-tuple linguistic generalized aggregation operators and their application in decision-making. Information Sciences, 236:1-16, 2013.

32. G. A. Miller. The magical number seven plus or minus two: some limitations on our capacity for processing information. Psychological Review, 63(2):81-97, 1956.

33. A. Motro and P. Anokhin. Fusionplex: resolution of data inconsistencies in the integration of heterogeneous information sources. Information Fusion, 7(2):176-196, 2006.

34. W Pedrycz. Granular Computing: Analysis and Design of Intelligent Systems. CRC Press, Francis Taylor Boca Raton, 2013.

35. D.H. Peng, C.Y. Gao, and L.L. Zhai. Multi-criteria group decision making with heterogeneous information based on ideal points concept. International Journal of Computational Intelligence Systems, 6(4):616625, 2013.

36. S.D. Pohekar and M. Ramachandran. Application of multi-criteria decision making to sustainable energy planning - a review. Renewable and Sustainable Energy Reviews, 8(4):365-381, 2004.

37. R.M. Rodríguez and L. Martínez. An analysis of symbolic linguistic computing models in decision making. International Journal of General Systems, 42(1):121136, 2013.

38. O. Senvar, G. Tuzkaya, and C. Kahraman. Multi criteria supplier selection using fuzzy PROMETHEE method. Studies in Fuzziness and Soft Computing, 313:21-34, 2014.

39. F. Ulengin, Y. Ilker Topcu, and S.O. Sahin. An integrated decision aid system for bosphorus watercrossing problem. European Journal of Operational Research, 134(1):179-192, 2001.

40. G.W. Wei. Some harmonic aggregation operators with 2-tuple linguistic assessment information and their application to multiple attribute group decision making. International Journal of Uncertainty, Fuzziness and Knowlege-Based Systems, 19(6):977-998, 2011.

41. P. Xidonas and J. Psarras. Equity portfolio management within the mcdm frame: A literature review. International Journal of Banking, Accounting and Finance, 1(3):285-309, 2009.

42. W. Yang and Z. Chen. New aggregation operators based on the Choquet integral and 2-tuple linguistic information. Expert Systems with Applications, 39(3):2662-2668, 2012. 
43. K. Zhang, G. Achari, and Y Y. Pei. Incorporating linguistic, probabilistic, and possibilistic information in a risk-based approach for ranking contaminated sites.
Integrated Environmental Assessment and Management, 6(4):711-724, 2010. 